convey how planetary exploration, and science in general, progresses as a human enterprise. Lorenz communicates what it is like to be a scientist involved with a current space mission, working with diverse colleagues and following your curiosity to make new discoveries.

Advances may come serendipitously, but they are usually hard-won following years of intense work, carried out with the risk of failure and research dead-ends. Some obstacles to progress are simple to overcome. For example, Lorenz recounts how, while working alone at night at an observatory, he was once held back by a crucial piece of equipment that lay behind a locked storage-room door. His eventual solution was to remove the door's hinges. Other challenges are greater, such as the discovery of an engineering problem with the radio transmitter on the

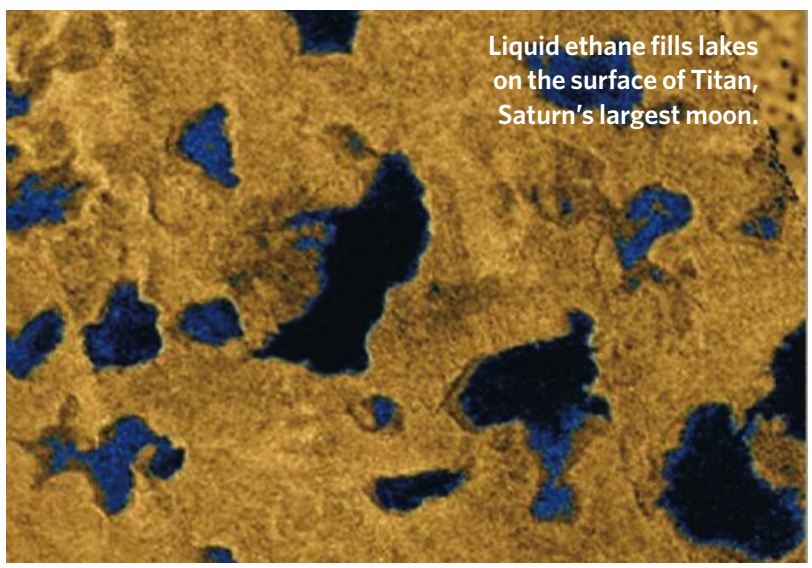

it from Earth nearly every night, new discoveries are regular. It is inevitable that any book on Titan is a little outof-date before it is released, but this reflects the vitality of the research.

We won't be able to book a ticket to Titan in the next few decades, but further robotic spacecraft will be sent to explore. A Titan orbiter could map the surface, observe the seasonal weather patterns and study the subsurface ocean. Balloon-borne detectors could examine the atmosphere and surface up close. And a new mission will add detail to our guidebook to Titan. Hopefully,

Huygens probe after its launch. It required a major effort to retarget and replan nearly the entire mission, involving hundreds of people and thousands of hours of work.

With the Cassini mission flying past Titan every few weeks and astronomers observing someone working on that mission will write an insider's account, like Titan Unveiled, to tell us how it all happened.

Henry Roe is an astronomer at Lowell Observatory, 1400 West Mars Hill Road, Flagstaff, Arizona 86001, USA.

\title{
How science hit the small screen
}

\begin{abstract}
Films of Fact
Science Museum, London

From 29 May to 2 November 2008.

Films of Fact: A History of Science in

Documentary Films and Television

by Timothy Boon

Wallflower Press: 2008. 224 pp.

$£ 45.00$ (hbk), £16.99 (pbk)
\end{abstract}

"Is it not a scandal, in this day and age, that there seems to be no place for continuing series of programmes about science?" asked veteran natural history broadcaster David Attenborough, lecturing on the future of public service television in London on 30 April. "If you want an informed society, there has to be a basic understanding of science."

An exhibition opening next week at London's Science Museum, Films of Fact, charts how science was introduced to the UK public in documentary films and on television in the early twentieth century, from the birth of these media to the 1960s.

Animals and plants featured in the first science films made for public viewing. Lasting for 56 seconds, the 1903 film Cheese Mites was first screened at London's Alhambra Music Hall as part of a musical and theatrical playbill that included ballet and magic tricks. Filmed down a microscope by amateur natural historian Francis Martin Duncan, the greatly magnified mites scuttle about. They may not seem riveting to our jaded eyes, but they stimulated demand for nature-based films. Producer Charles Urban exploited this commercial potential in a series of photomicrography films called 'The Unseen World: Revealing Nature's Closest Secrets by Means of the Urban-Duncan Micro-Bioscope', which included The Circulation of the Protoplasm of the Canadian Waterweed (1903). Nature series quickly became established as a popular genre and remain so today, from movies of meerkat antics to marching penguins.

The most successful nature film series

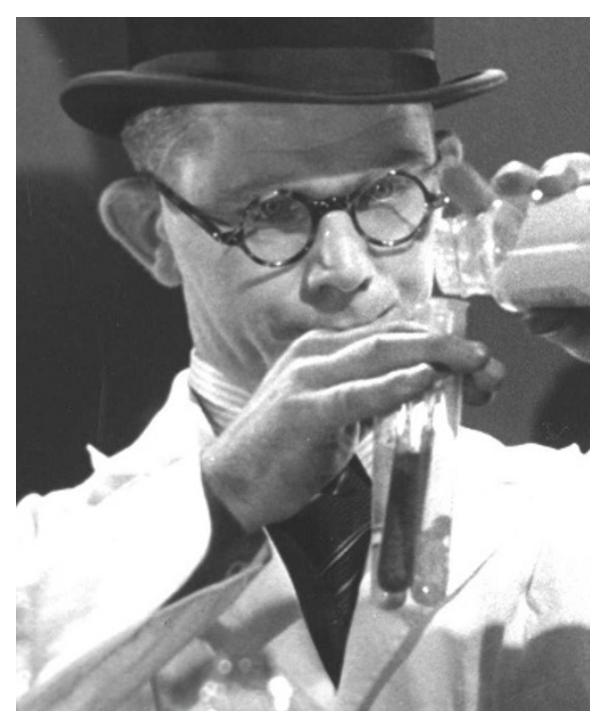

Comic chemistry: Rotha's 1938 New Worlds for Old. before the Second World War was Secrets of Nature (1922-33), produced by British Instructional Films. Its successor was Secrets of Life (1934-50). Celebrated cameraman Percy Smith, a clerk at the UK government's Department of Education, worked on both series. He specialized in filming through microscopes or glass aquaria in his London greenhouse, using a timing device he made from a cuckoo clock to record plant growth with time-lapse photography.

Television programming about science took off in the mid-1950s in the United Kingdom, two decades after broadcasting began there in 1936. Some science series were designed to teach. Producers and scientists worked together, mostly in live broadcasts such as Eye on Research (1957-61), which took cameras into research establishments.

As television became a mass medium, scientists tried to influence how broadcasters represented science, but they did not always get a good reception. "Priority must be given to the medium rather than scientific pedantry," ruled Aubrey Singer, head of the BBC's science department in 1966. "The aim of scientific programming ... is not necessarily the propagation of science" but "an enrichment of the audience experience". Similar attitudes prevail today.

Other documentaries, many commercially sponsored, explored how new technologies were transforming everyday life. Influential film-maker Paul Rotha's 1933 documentary Contact, sponsored by Imperial Airways, captures aeroplane manufacture using beguiling and original cinematography. From the 
1930s, Rotha and others used angled shots and rapid editing - techniques pioneered by Russian film directors and cinematographers - to celebrate innovations such as aircraft, telephone networks, electricity and express railways. Enthusiasm for technology remains a strong driver of scientific film and television.

The Depression of the 1930s stimulated documentaries in which scientists identified social problems and proposed solutions. In 1936, Enough to Eat? relayed the shocking conclusion of nutritionist John Orr, in a study entitled Food, Health and Income for the UK Ministry of Agriculture, that half the population of the United Kingdom was too poor to maintain a healthy diet.

In the exhibition, film and television clips are projected onto a screen, and hundreds of other clips from 38 films can be accessed interactively though two computer stations. Pieces of film-making equipment are also on show: a Moy and Bastie cine camera made to
Urban's design; a Zeiss microscope of the type used by Smith; a Marconi IV studio television camera used in the 1960s; a Moviola editing machine; and a 1930s Newman Sinclair cine camera.

Chief curator of the Science Museum, Timothy Boon, has written a well-researched book that provides background detail for historians of UK science film-making during this period. Other researchers are tackling French, Russian and US depictions of science on film and television, plundering those nations' archives with equal diligence. Once these studies are complete, it would be valuable to combine them into a global account of science on screen.

"My ambition for the show," says Boon, "is that by seeing different types of science films, people will become more informed consumers of science television now." Hopefully, greater knowledge of how science programming developed will guide decisions about its future.

Colin Martin is a writer based in London.

\section{Super clothes with special powers}

Superheroes: Fashion and Fantasy
The Metropolitan Museum of Art,
New York
Until 1 September 2008 .

Shazam! With a bolt of lightning, 12-year-old Billy Batson turns into Captain Marvel, a superhero with the wisdom of Solomon, the strength of Hercules, the stamina of Atlas, the power of Zeus, the courage of Achilles and the speed of Mercury - legendary heroes whose initials spell the magic command that gives Marvel his superhuman powers. With a similar spell, the Metropolitan Museum of Art in New York has transformed one of its galleries into a shrine to modern mythical titans. Its new exhibition, Superheroes: Fashion and Fantasy, is craftily planted in the midst of its Greek and Roman art collection. Marble statues of Hercules, Diana and Perseus along with amphorae depicting muscular runners and wrestlers surround their fantastic descendents: Superman, Wonder Woman, Iron Man and The Incredible Hulk.

Extending our fascination with extremes of strength, endurance, speed and courage, the exhibition shows how the exaggerated forms of superheroes are mirrored in haute couture. It also demonstrates how inventors have incorporated aspects of superheroism - elasticity, rigidity and aerodynamic grace - into more practical kinds of clothing, such as

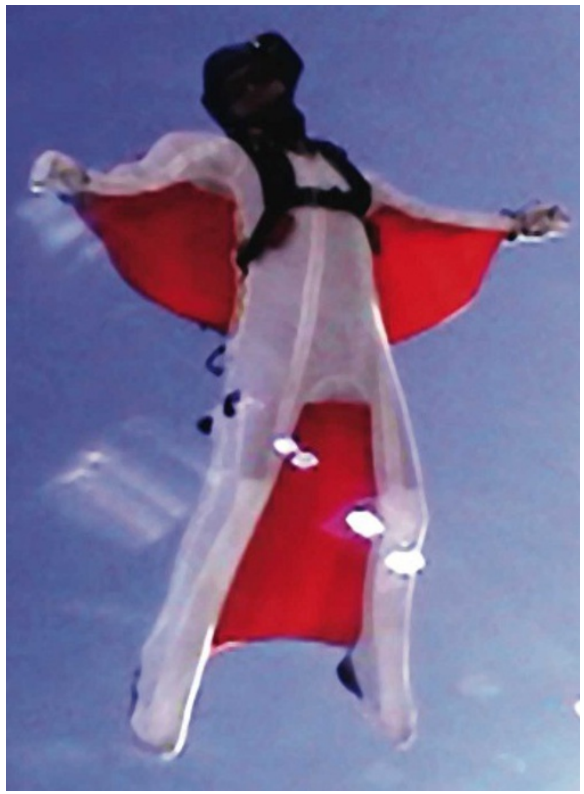

Sky-dive like a superhero in Atair's soft wing suit.

swimsuits, space suits and wing suits.

Superheroes might be mutants, armoured men, shape-shifters or gadgeteers; fashion designers draw inspiration from them all. Mutants - usually the result of a lab accident, genetic mishap or nuclear bomb blast - often appear in near-monstrous forms, such as The Incredible Hulk. Designers have transmuted these creations into garments of unusual elegance and beauty. A 1997 green and turquoise gown by Thierry Mugler, for example, seems to be destined for a creature that is part bird, part crustacean; long-sleeved with a flowing train, it consists almost entirely of feathers, its middle a segmented carapace. Spider-Man stirs skiwear designer Spyder, whose web-patterned race suits are on display, as well as Giorgio Armani, whose offerings include a 1990 beige evening dress sheathed in a delicate web of insect-adorned netting.

Body armour also enthralls avant-garde fashionistas. The shield of superheroes such as Iron Man - played in this spring's blockbuster by Robert Downey Jr, whose LED-eyed fibreglass costume is on show here - finds new forms in such ensembles as Gareth Pugh's 2007 leather-and-synthetic dress. With sleeves formed of shiny, triangular black panels, it resembles a solar-powered bat. Speaking of bats, the show does a nice sideline on stylish dominatrix wear, as epitomized by Michelle Pfeiffer in stilettos and clawed black gloves in the 1992 film Batman Returns, whose Catwoman costume spawned slinky offshoots by Gianni Versace.

Superheroes can also inspire real-world science. The Flash, created in 1940, possessed the power of super speed, as symbolized by his sleek scarlet bodysuit. Several outfits on display may increase the speed of the wearer. The outer texture of Speedo's Fastskin FS-Pro swimsuit mimics shark skin, which the company claims reduces drag by around $4 \%$. More impressive is Dava Newman's body-hugging, flexible BioSuit, a space suit that relies on the mechanical counter-pressure provided by tight layers of material to protect the wearer from the vacuum of space. Newman, a professor of aeronautics and astronautics at the Massachusetts Institute of Technology, intends the BioSuit to replace bulkier, gas-pressurized space suits.

Most impressive are the wing suits developed by Atair Aerospace. A pilot strapped to the rigid wing suit - two polyethylene wings filled with jet fuel, powering turbines that provide almost 500 newtons of thrust - can fly at speeds of up to 350 kilometres per hour. Because the wing suit's wearer cannot be detected by radar, the company is now developing a military model with which spies could jump out of an aeroplane in one country and fly to another. Inventor Daniel Preston, the founder of Atair, says he has sky-dived hundreds of times in either the rigid wing suit or a non-fuelled soft suit, which has fabric webbing between the legs and arms. No other experience so exactly captures life as a superhero, Preston says. "It's as close as you can get to being a bird."

Josie Glausiusz is a writer based in New York. 